\section{Coeliac disease in association with inflammatory bowel disease}

Sir,

Patients with the combination of coeliac disease (CD) and inflammatory bowel disease are uncommon. Several authors in analysing the prevalence of these two conditions have suggested a more than chance association between them and urged the reporting of patients where both pathologies had been clearly demonstrated. ${ }^{1-3} \mathrm{We}$ describe a further two cases of CD with inflammatory bowel disease, one of whom also had sclerosing cholangitis.

The first case was that of a 16 year old male who presented with a 4-month history of abdominal pain, diarrhoea and a $6.4 \mathrm{~kg}$ weight loss. Sigmoidoscopy, barium enema and small bowel follow-through were normal but a small bowel biopsy showed partial villous atrophy. The patient had a good symptomatic and histological response to a gluten-free diet. Three months later blood stained diarrhoea developed. Colonoscopy revealed multiple discrete aphthous ulcers throughout the colon and serial colonic biopsies showed a chronic inflammatory mucosal infiltrate, goblet cell depletion and incipient crypt abscesses. There was a raised immunoglobulin-G level of $55 \mathrm{~g} / 1$ (normal $7.5-16.5 \mathrm{~g} / \mathrm{l}$ ) and positive smooth-muscle and reticulin antibodies at a titre of $>1: 160$. Ultrasound examination of the upper abdomen revealed moderate dilatation of the common bile duct with extensive portal, peripancreatic, para-aortic and mesenteric lymphadenopathy. Endoscopic retrograde cholangiography showed evidence of sclerosing cholangitis. At laparotomy, moderate hepatosplenomegaly, and extensive intraabdominal lymphadenopathy were noted. Histologically the lymph nodes showed non-specific reactive hyperplasia and wedge biopsy of the liver showed changes consistent with large or intermediate bile duct obstruction. A diagnosis of Crohn's colitis with associated sclerosing cholangitis and reactive abdominal lymphadenopathy was made. The patient was treated with sulphasalazine in addition to the gluten-free diet and has remained well for a follow-up period of 2 years.

The second case was a 32 year old woman who presented with a 6-month history of diarrhoea, $16 \mathrm{~kg}$ weight loss and carpo-pedal spasm. The serum calcium was $1.8 \mathrm{mmol} / 1$ (normal $2.2-2.6 \mathrm{mmol} / \mathrm{l}$ ) with a normal serum phosphate and albumen. A small bowel biopsy revealed subtotal villous atrophy and a gluten-free diet was instituted. The diarrhoea settled and there was a $10 \mathrm{~kg}$ weight gain. Repeat small bowel biopsy showed a normal villous architecture which reverted to subtotal villous atrophy with gluten challenge. Thirteen years later the patient complained of passing large volumes of blood and mucus per rectum. Colonoscopy showed oedematous hyperaemic mucosa throughout the colon and multiple colonic biopsies confirmed chronic inflammatory bowel disease. There was a good response to sulphasalazine. Apart from occasional exacerbations of the ulcerative colitis the patient remains well after 7 years of follow-up.

In the three series ${ }^{1-3}$ where more than one patient with both $C D$ and inflammatory bowel disease have been reported, the authors have reported a 2- to 10-fold increase in prevalence of patients with both conditions than would be expected by chance. The finding of a significant association between these two conditions would be of importance as their combination in an individual patient could produce a confusing clinical picture. The two cases described above add further evidence to support an association between $\mathrm{CD}$ and inflammatory bowel disease.

Kyran Bulger

Mairead Griffin

Peter Dervan

John Lennon

John Crowe

Departments of Gastroenterology and Pathology, Mater Misericordiae Hospital,

Dublin, Ireland.

\section{References}

1. Kitis, G., Holmes, G.K.T., Cooper, B.T., Thompson, H. \& Allan, R.N. Association of coeliac disease and inflammatory bowel disease. Gut 1980, 21: 636-641.

2. Gillberg, R., Dotevall, G. \& Ahren, C. Chronic inflammatory bowel disease in patients with coeliac disease. Scand J Gastroenterol 1982,17: 491-496.

3. Breen, E.G., Coghlan, G., Connolly, E.C., Stevens, F.M. \& McCarthy, C.F. Increased association of ulcerative colitis and coeliac disease. Ir J Med Sci 1987, 156: $120-121$.

\section{Hypomagnesaemia on antibiotic therapy}

Sir,

I recently had occasion to review the literature on the association between hypocalcaemia and tetany due to hypomagnesaemia because of prolonged treatment with aminoglycosides. ${ }^{1}$ We would like to report a case occurring in a 48 year old man in remission for 4 months with Hodgkin's lymphoma. The patient presented with pyrexia. Physical examination did not disclose any enlarged lymph nodes but abdominal examination revealed hepatomegaly and splenomegaly. No haematological, biochemical or microbiological abnormalities were present in blood. Computed tomography scans revealed enlarged mesenteric lymph nodes. A diagnosis of relapse of his disease was made and he completed a cycle of oral chemotherapy (MOPP) $)^{2}$ with pancytopaenia after treatment days. He developed clinical septicaemia but cultures of blood, sputum and urine always showed no growth. Amikacin and ceftazidime were given for the first 20 days and piperacillin and metronidazole for the next 25 days.

His chest X-rays showed a mass in the right upper lobe and rifampicin, isoniazid, ethambutol and dibekacin and then streptomycin were also given.

After 20 days he developed tetany with a serum calcium of $1.9 \mathrm{mmol} / 1$ (normal $2.1-2.5$ ), serum albumin $32 \mathrm{~g} / 1$ and potassium $2.8 \mathrm{mmol} / \mathrm{l}$. Despite treatment with calcium gluconate intermittent tetany persisted. Because of low 
serum magnesium $(0.4 \mathrm{mmol} / \mathrm{l}$; normal range 0.7 $1.0 \mathrm{mmol} / \mathrm{l}$ ) calcium gluconate was discontinued and magnesium sulphate was administered.

The tetany responded immediately but his condition gradually worsened and he died The diagnosis of Hodgkin's lymphoma was confirmed at autopsy. The hypomagnesaemia was due to renal tubular damage from aminoglycosides. ${ }^{3}$

Since magnesium deficiency impairs secretion of parathyroid hormone and may render bone and kidney resistant to the effect of the hormone, hypocalcaemia can be reversed only by administration of magnesium. ${ }^{4}$

The syndrome may occur during prolonged courses of aminoglycosides and monitoring of serum potassium and serum calcium as well as serum magnesium concentration is therefore recommended for such patients.

\section{Salvatore Campo Enrico Breda Marco Di Girolamo Department of Medicine, Divisione di Medicina Generale, Ospedale Patebenefratelli, Isola Tiberina, 00100 Roma, Italy.}

\section{References}

1. Wilkinson, R., Lucas, G.L., Heath, D.A., Franklin, I.M. \& Boughtan, B.J. Hypomagnesaemic tetany associated with prolonged treatment with aminoglycosides. $\mathrm{Br} \mathrm{Med} J$ 1986, 292: 818.

2. Bonadonna, G., Fossati, V. \& De Lena, M. Cyclic delivery of MOPP and ABVD combinations in stage IV Hodgkin's disease: rationale background studies and recent results. Cancer Treatment Reports 1982, 66: 881.

3. Freedman, D.B., Shannan, M., Dandona, P., Prentice, H.G. \& Hoffbrand, A.V. Hypoparathyroidism and hypocalcaemia during treatment for acute leukaemia. Br Med J 1982, 284: 700.
4. Rude, R.K., Oldham, S.B., Sharp, C.F. \& Singer, F.R. Parathyroid hormone secretion in magnesium deficiency. J Clin Endocrinol Metab 1978, 47: 800.

\section{Transfer from recovery room to ward}

Sir,

From an anaesthetic point of view, a patient can be discharged from the recovery room (a) when he is able to maintain adequate alveolar ventilation and can clear his airway; (b) he is awake, alert, well orientated in space and time and can make his wants and needs known, and (c) if he is able to maintain adequate tissue perfusion, without continuous monitoring and support of his cardio-vascular system. Patients with unstable cardio-vascular systems should not be moved, unless they are well stabilized

From the surgical point of view, if the patient is not expected to need close surgical surveillance he can be transferred to his ward. A trained nurse preferably should accompany the patient whenever necessary.

The author's (Salim) recovery score (Table I) assesses three physical signs, i.e. 'ABC of recovery' - Airways, Behaviour, Consciousness. A score of eight is the minimum for discharge from the recovery room in most instances.

We assessed this ABC score in more than 2000 patients aged one to 80 years to judge its effectiveness. We found that this score is effective for assessing recovering patients and sending them to the wards.

It is a great help to trainee doctors and students. We have now made a printed chart in our recovery room for guidance of trainees, doctors and nurses.

Colonel M. Salim Army Medical College, Rawalpindi, Pakistan.

\section{References}

1. Anis \& Salim, M. In: Anaesthesia and Patient Care. Army Press, 6 Zafar Akbar Road, Lalazar Rawalpindi, Pakistan, 1983, p 1422.

2. Salim, M. Postanesthetic recovery. Pakistan Medical Journal 1987, 46-50.

Table I Postanaesthetic recovery score

Salim's $A B C$ recovery score

Score for response

\begin{tabular}{|c|c|c|c|c|}
\hline Physical signs & 3 & 2 & 1 & 0 \\
\hline rways & $\begin{array}{l}\text { Patient can cough } \\
\text { or cry }\end{array}$ & $\begin{array}{l}\text { Maintains clear } \\
\text { airway without } \\
\text { holding the jaw }\end{array}$ & $\begin{array}{l}\text { Holding of } \\
\text { jaw needed }\end{array}$ & $\begin{array}{l}\text { Holding of jaw } \\
\text { and other measures } \\
\text { taken to maintain } \\
\text { airways }\end{array}$ \\
\hline haviour & $\begin{array}{l}\text { Patient can } \\
\text { lift the head }\end{array}$ & $\begin{array}{l}\text { Can open the } \\
\text { eyes and show } \\
\text { his tongue }\end{array}$ & $\begin{array}{l}\text { Some } \\
\text { non-purposeful } \\
\text { movements }\end{array}$ & $\begin{array}{l}\text { No movements } \\
\text { at all }\end{array}$ \\
\hline onsciousness & $\begin{array}{l}\text { Fully awake, } \\
\text { can talk, } \\
\text { well oriented }\end{array}$ & $\begin{array}{l}\text { Awake but } \\
\text { needs support }\end{array}$ & $\begin{array}{l}\text { Responds } \\
\text { to stimuli } \\
\text { only }\end{array}$ & No response \\
\hline
\end{tabular}

